\title{
Duodenal Gastrointestinal
}

\section{Stromal Tumor Treated by}

Wedge Resection in a Patient

with Neurofibromatosis Type 1:

Report of a Case and Review of

the Japanese Literature

\author{
Hideya Takeuchi ${ }^{a, c}$ Toshihumi Matsumoto ${ }^{a, c}$ \\ Tetsuya Kusumoto $^{a, c}$ Yasuji Yoshikawab,c Yoichi Muto ${ }^{a, c}$ \\ ${ }^{a}$ Department of Surgery, ${ }^{b}$ Department of Pathology and ${ }^{c}$ Clinical Research \\ Institute, National Hospital Organization Beppu Medical Center, Beppu, Japan
}

\section{Key Words}

Gastrointestinal stromal tumor - Neurofibromatosis type $1 \cdot$ Wedge resection

\begin{abstract}
A case of duodenal gastrointestinal stromal tumor (GIST) treated by wedge resection in a patient with neurofibromatosis type 1 (NF-1) is reported. A 55-year-old man with a history of NF-1 was admitted for surgery for a duodenal tumor. Upper gastrointestinal endoscopy revealed a $2.5 \mathrm{~cm}$ duodenal submucosal tumor. Abdominal computed tomography showed a homogenously enhanced mass in the third portion of the duodenum. The patient successfully underwent wedge resection of the duodenal tumor. Histological examination revealed proliferation of spindle tumor cells arranged in a bundle pattern. This tumor was immunohistochemically positive for c-Kit and CD34, and negative for S-100 and a-SMA. A mitotic count showed 3 mitoses per 50 high-power fields. The tumor was diagnosed as a low-risk GIST. The patient's postoperative course was uneventful. GIST in a patient with NF-1 is rare, only 27 cases being reported in the Japanese literature.
\end{abstract}

\section{Introduction}

Neurofibromatosis type 1 (NF-1), also called von Recklinghausen's disease, is the most common autosomal dominant disorder with a prevalence of approximately 1 in 3,000 individuals. NF-1 is associated with a variety of benign and malignant neoplasms [1]. 
Malignant tumors have been reported four times as often in NF-1 patients as in the general population. A gastrointestinal abnormality is reported to occur in up to $10-20 \%$ of NF-1 patients [2].

Although gastrointestinal stromal tumor (GIST), arising from Cajal's cells and expressing c-Kit, is the most common gastrointestinal mesenchymal tumor, the occurrence of GIST in patients with NF-1 is rare. A case of GIST in a NF-1 patient is reported, and the Japanese literatures is reviewed to elucidate its clinicopathological characteristics.

\section{Case Report}

A 55-year-old man with a history of NF-1 at the age of 20 years had been followed for GIST in the duodenum at another hospital. His mother also suffered from NF-1. Since the GIST was found to have grown to $2.5 \mathrm{~cm}$, he was admitted to our department for surgery. Physical examination revealed multiple cafe au lait spots and discrete cutaneous neurofibromas over the patient's body. Preoperative laboratory tests were normal. Upper gastrointestinal endoscopy revealed a submucosal tumor, covered with normal mucosa with a central depression in the third portion of the duodenum (fig. 1). Abdominal computed tomography showed a homogenously enhanced mass in the duodenum and no evidence of metastases in the abdomen (fig. 2). The patient was successfully treated with wedge resection of the duodenal tumor. At laparotomy, no liver or lymph node metastases were found, and a submucosal tumor with a clear border was found in the duodenum about $7 \mathrm{~cm}$ above the ligament of Treitz. After the Kocher method had been performed, the tumor, with a $1 \mathrm{~cm}$ circumference of normal full-thickness duodenal mucosa, was extracted, and the duodenum was sutured using a two-layer method. The tumor, measuring $25 \times 25 \times 23 \mathrm{~mm}$, was covered by a normal mucosa, and the cut surface was smooth and white in appearance. Histological examination revealed proliferation of spindle tumor cells arranged in a bundle pattern (fig. $3 \mathrm{a})$. The mitotic count showed 3 mitoses per 50 high-power fields. Immunohistochemical stains were positive for c-Kit (fig. 3b) and CD34 (fig. 3c), and negative for S-100 and $\alpha$-SMA. The tumor was diagnosed as a low-risk GIST. The postoperative course was uneventful, and the patient remains completely asymptomatic after 24 months.

\section{Discussion}

NF-1, which was first reported by von Recklinghausen in 1882, is characterized by abnormal skin pigmentation, cutaneous and plexiform neurofibromas, skeletal dysplasias, and Lisch nodules. NF-1 is caused by mutations of the NF-1 gene on chromosome 17, which encodes neurofibromin, a member of the GTPase-activating protein ras regulatory family [1].

GIST is the most common gastrointestinal mesenchymal tumor, accounting for $80 \%$ of these neoplasms. Patients' mean age ranges from 55 to 65 years, and there is a slight male predominance [3]. GIST is thought to increase by the activation of tyrosine kinase of the Kit receptor through mutation of the protooncogene c-Kit gene [4]. To the best of our knowledge, only 28 cases of GIST associated with NF-1 have been reported, and they are summarized in table 1 [5-12]. There were 14 males and 14 females (male/female ratio 1.0). Their median age was 56.0 years (range $22-74$ years). According to the risk criteria of GIST [2], 7 were at high risk, 2 at intermediate risk, and 10 at very low/low risk. In 4 cases the tumor was found incidentally during unrelated surgery. 6 cases needed emergent surgery because of bleeding, perforation, or bowel obstruction. 4 cases had synchronous combined malignant disease. All cases developed in the small intestine, and most cases were multiple synchronous primary lesions, while GISTs in non-NF-1 patients occur as solitary lesions, most commonly in the stomach (60-70\%), followed by the small intestine $(20-30 \%)$ [3]. 
Recently, dramatic improvements have been achieved using imatinib mesylate (formerly STI571, Gleevec in the United States/Glivec in Europe) in cases of metastasis or recurrence of GIST [13]. Imatinib mesylate works by inhibiting active mutant c-Kit tyrosine kinase, which appears to play a central part in the pathogenesis of GIST. It is known that the likelihood of response to imatinib mesylate is strictly related to the c-Kit mutational pattern. However, Nemoto et al. [1] reported absence of c-Kit mutation in GIST in an NF-1 patient. These findings support the idea that different mechanisms underlie the tumorigenesis of GIST based on the neurofibromin gene disorder in NF-1 patients and non-NF-1 patients, and treatment of GIST and evaluation of the efficacy of imatinib mesylate should be distinguished between NF-1 and non-NF-1 patients [14]. GISTs without c-Kit mutations appear to respond less well than those with c-Kit mutations. Further examination of the utility of imatinib mesylate in a larger number of NF-1 patients with GIST is needed.

Since lymph node metastasis is very rare in cases with GIST, it is recognized that lymph node dissection is unnecessary, and full-thickness local excision is recommended [3]. Duodenal wedge resection to the duodenal GIST far from the ampulla is considered an appropriate surgical procedure in terms of morbidity and curability without any symptoms.

GIST in a patient with NF-1 is rare; the present case is the 28th reported case in the Japanese literature. Patients with NF-1, particularly those presenting with gastrointestinal symptoms, should be investigated for GIST. In NF-1 patients with GIST, further investigations of the entire body, especially the small intestine, are needed preoperatively and intraoperatively. Use of imatinib mesylate in this subset of patients with GIST may not be appropriate. 
Table 1. Summary of 28 reported cases of GIST in patients with NF-1 in Japan

\begin{tabular}{lc}
\hline Characteristics & Number of patients \\
\hline Sex & \\
$\quad$ Male & $14(50.0 \%)$ \\
Female & $14(50.0 \%)$ \\
Median age, years (range) & $56.0(22-74)$ \\
Primary site & \\
$\quad$ Small intestine & $28(100 \%)$ \\
Number of primary tumors & $18(64.3 \%)$ \\
$\quad$ Multiple & $10(36.7 \%)$ \\
Single & $6.4(1.2-25)$ \\
Median tumor size, cm (range) & $7(36.8 \%)$ \\
Risk stratification (n = 19) & $2(10.5 \%)$ \\
$\quad$ High & $10(52.7 \%)$ \\
Intermediate & \\
Very low/low & $2(7.1 \%)$ \\
Synchronous combined malignant disease $(\mathrm{n}=4)$ & $2(7.1 \%)$ \\
$\quad$ Rectal carcinoma & \\
Duodenal carcinoma & $3(10.7 \%)$ \\
Reason for emergent operation (n = 6) & $2(7.1 \%)$ \\
$\quad$ Bleeding & $1(3.6 \%)$ \\
Perforation & $4(14.3 \%)$ \\
Bowel obstruction &
\end{tabular}

Fig. 1. Upper gastrointestinal endoscopy shows a submucosal tumor with an ulcer scar formed at the top in the duodenal third portion.

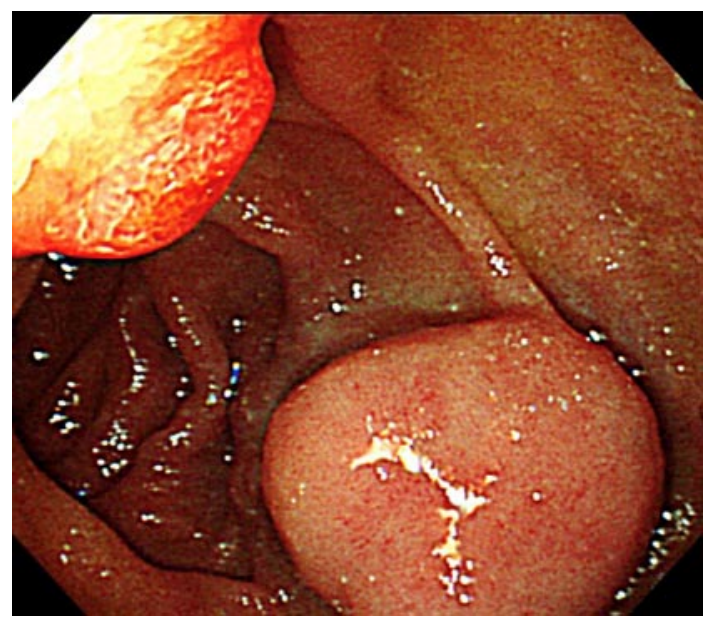


Fig. 2. Computed tomography image of the abdomen shows a homogenously enhanced mass in the duodenal second portion with no evidence of direct invasion of neighboring organs or liver metastases.

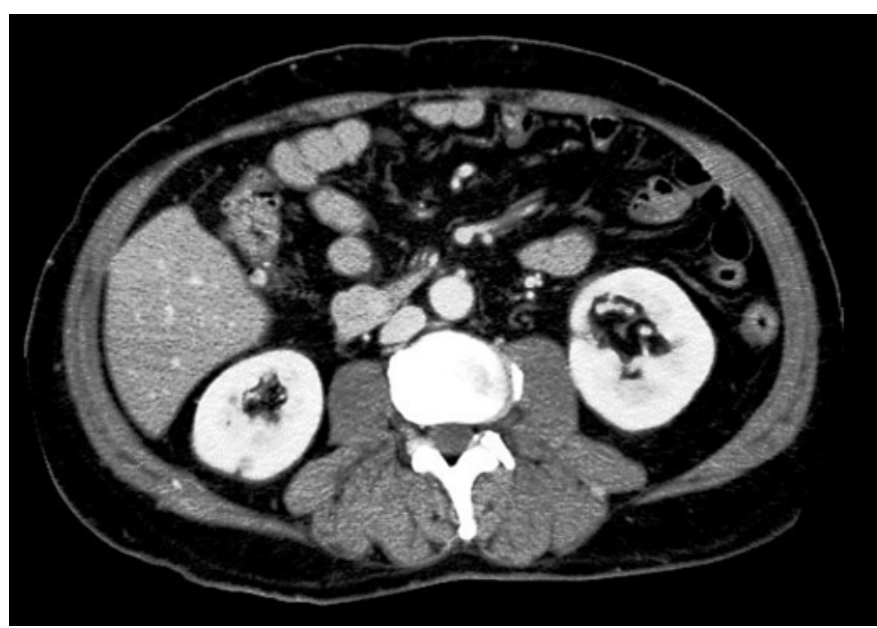




\begin{tabular}{r|l|l|l} 
Case Reports $h$ Ch & $\begin{array}{l}\text { Case Rep Gastroenterol 2009;3:343-349 } \\
\text { Dol: } 10.1159 / 000255019\end{array}$ & Published online: November 20, 2009 & $\begin{array}{l}\text { I 2009 S. Karger AG, Basel } \\
\text { ISSN 1662-0631 } \\
\text { www.karger.com/crg }\end{array}$ \\
& & & \\
\hline
\end{tabular}

Fig. 3. Histological examination reveals tumors were composed of spindle cells arranged in a bundle pattern $(\mathbf{a}, \times 400)$, and the cells are immunohistochemically positive for c-Kit $(\mathbf{b}, \times 400)$ and CD34 (c, $\times 400)$.
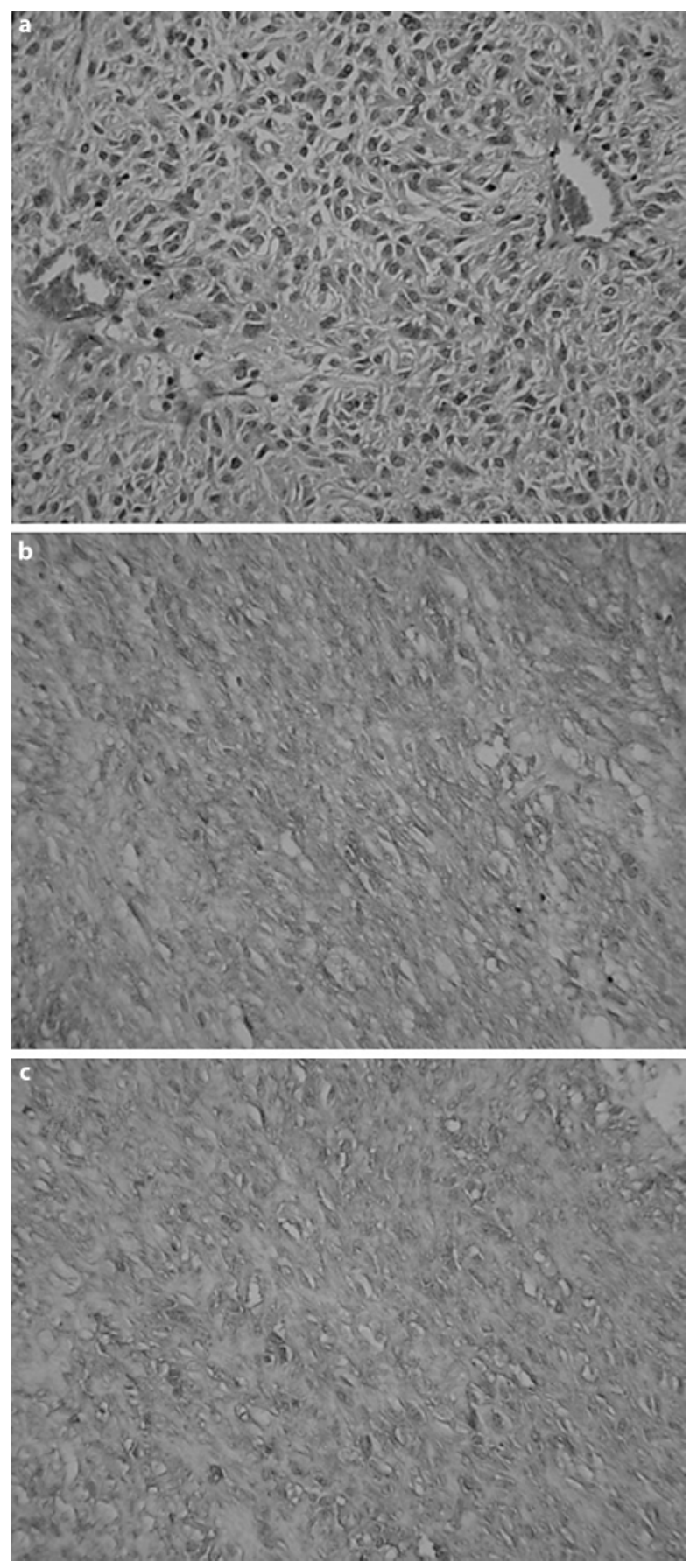


\section{References}

1 Nemoto H, Tate G, Schirinzi A, Suzuki T, Sasaya S, Yoshizawa Y, Midorikawa T, Mitsuya T, Dallapiccola B, Sanada Y: Novel NF1 gene mutation in a Japanese patient with neurofibromatosis type 1 and a gastrointestinal stromal tumor. J Gastoenterol 2006;41:378-382.

-2 Fletcher CD, Berman JJ, Corless C, Gorstein F, Lasota J, Longley BJ, Miettinen M, O'Leary TJ, Remotti H, Rubin BP, Shmookler B, Sobin LH, Weiss SW: Diagnosis of gastrointestinal stromal tumors: A consensus approach. Hum Pathol 2002;33:459-465.

-3 Agaimy A, Wunsch PH, Sobin LH, Lasota J, Miettinen M: Occurrence of other malignancies in patients with gastrointestinal stromal tumors. Semin Diagn Pathol 2006;23:120-129.

-4 Rubin BP, Singer S, Tsao C, Duensing A, Lux ML, Ruiz R, Hibbard MK, Chen CJ, Xiao S, Tuveson DA, Demetri GD, Fletcher CD, Fletcher JA: KIT activation is a ubiquitous feature of gastrointestinal stromal tumors. Cancer Res 2001;61:81188121.

5 Ikuta S, Yasui C, Aihara T, Yoshie H, Bandoh T, Mitsunobu M, Sugihara A, Yamanaka N: A case of von Recklinghausen's disease complicated by carcinoma of the papilla of Vater and multiple gastrointestinal stromal tumors of the jejunum (in Japanese with English abstract). Jpn J Gastroenterol Surg 2007;40:599-604

6 Zennami S, Sugiura M, Terashita Y, Yuki D: A case of multiple gastrointestinal stromal tumors of the small intestine with von Recklinghausen's disease (in Japanese). Geka 2005;67:1752-1756.

7 Yamashita S, Yamamoto H, Yamada K, Kohira T, Wada T, Kawamura M, Yoshii S, Kitagawa T, Sakanishi Y, Arai H: A case of gastrointestinal stromal tumor of the jejunum associated with von Recklinghausen disease (in Japanese). J Seirei Mikatahara General Hosp 2005;9:79-83.

8 Chin S, Fujita R, Narita T, Kawa Y, Murata J, Kameoka S: Multile jejunal gastrointestinal stromal tumors in a patient with von Recklinghausen's disease (in Japanese with English abstract). J Jpn Surg Assoc 2006;67:1596-1599.

9 Ishii J, Kaneko H, Tamura A: A case of gastrointestinal stromal tumors with von Recklinghausen's diseas (in Japanese). J Jpn Surg Assoc 2006;31:698-702.

10 Nakakimura S, Takahashi S, Hirose K, Konno T, Saji Y: Laparoscopically assisted intestinal resection of the multiple GIST in a patients with von Recklinghausen's disease (in Japanese with English abstract). J Jpn Soc Endo Surg 2006;11:645-650.

11 Komeda K, Hiramatsu M, Fujita Y, Nishimura H, Tatsumi Y, Tanaka S, Egashira $\mathrm{Y}$, Tanigawa N: A case report of multiple gastrointestinal stromal tumors of the jejunum with von Recklinghausen's diseas (in Japanese with English abstract). Jpn J Gastroenterol Surg 2007;40:209-214.

12 Seki H, Kurihara E: A case of multiple gastrointestinal stromal tumors of the small intestine in a patient with von Recklinghausen's disease (in Japanese with English abstract). J Jpn Surg Assoc 2007;68:1171-1174.

13 Demetri GD, von Mehren M, Blanke CD, Van den Abbeele AD, Eisenberg B, Roberts PJ, Heinrich MC, Tuveson DA, Singer S, Janicek M, Fletcher JA, Silverman SG, Silberman SL, Capdeville R, Kiese B, Peng B, Dimitrijevic S, Druker BJ, Corless C, Fletcher CD, Joensuu H: Efficacy and safety of imatinib mesylate in advanced gastrointestinal stromal tumors. N Engl J Med 2002;347:472-480.

14 Frost MJ, Ferrao PT, Hughes TP, Ashman LK: Juxtamembrane mutant V560GKit is more sensitive to Imatinib (STI571) compared with wild-type c-kit whereas the kinase domain mutant D816VKit is resistant. Mol Cancer Ther 2002;1:11151124. 